\title{
Respiratory effects of lipopolysaccharide-induced inflammatory lung injury in mice
}

\author{
D.S. Faffe*, V.R. Seidl*, P.S.C. Chagas*, V.L. Gonçalves de Moraes", \\ V.L. Capelozzi ${ }^{+}$, P.R.M. Rocco*, W.A. Zin*
}

Respiratory effects of lipopolysaccharide-induced inflammatory lung injury in mice. D.S. Faffe, V.R. Seidl, P.S.C. Chagas, V.L. Gonçalves de Moraes, V.L. Capelozzi, P.R.M. Rocco, W.A. Zin. C) ERS Journals Ltd 2000.

ABSTRACT: The pathogenic mechanisms of lipopolysaccharide (LPS)-induced lung injury have not been classified. This study examined the physiological changes after endotoxin inhalation and related those to features of pulmonary inflammation in mice.

Pulmonary mechanics, histopathology, and bronchoalveolar lavage fluid (BALF) from BALB/c mice were analysed at different occasions $(3,24,48$ and 72 h) after inhalation of saline or LPS from Excherichia coli $\left(0.3(\mathrm{LO} .3)\right.$ or $\left.10 \mathrm{mg} \cdot \mathrm{mL}^{-1}(\mathrm{L10})\right)$. Mice were sedated, anaesthetized, and ventilated. After chest wall resection static (Est) and dynamic $\left(E\right.$ dyn) elastances, $\Delta E(E$ dyn- $E$ st $)$, resistive $\left(\Delta P_{1}\right)$ and viscoelastic/ inhomogeneous pressures $\left(\Delta P_{2}\right)$, and $\Delta P_{1}+\Delta P_{2}(\Delta P$ tot $)$ were obtained by end-inflation occlusion method. Lungs were prepared for histopathology. In parallel groups, tumour necrosis factor (TNF)- $\alpha$, neutrophils, and protein were evaluated in the BALF.

L0.3 and L10 showed a time-dependent production of TNF- $\alpha$ preceding a massive neutrophil infiltration. In L10 BALF there was an increase in protein level at 24 and 48 h. Est and $E$ dyn increased early in L0.3 $(65 \%, 63 \%)$ and $L 10(41 \%, 51 \%)$. In L10 $\Delta E, \Delta P 2$, and $\Delta P$ tot showed a gradual rise. At $72 \mathrm{~h}$ all groups were similar. L0.3 showed an early increase in cellularity, which returned to normal at $72 \mathrm{~h}$. L10 presented the same pattern with the cell count remaining elevated until $72 \mathbf{~ h}$.

In conclusion, lipopolysaccharide inhalation led to elastic and viscoelastic pulmonary changes together with tumour necrosis factor- $\alpha$ production and neutrophil infiltration in mouse lung.

Eur Respir J 2000; 15: 85-91.
*Laboratory of Respiration Physiology, Carlos Chagas Filho Biophysics Institute and \# Dept of Medical Biochemistry, Federal University of Rio de Janeiro, Rio de Janeiro, Brazil. 'Dept of Pathology, Faculty of Medicine, São Paulo University, São Paulo, Brazil.

Correspondence: W.A. Zin Universidade Federal do Rio de Janeiro Centro de Ciencias da Saúde Instituto de Biofisica Carlos Chagas Filho Ilha do Fundão 21949-900 - Rio de Janeiro RJ Brazil. Fax: 55212808193 or 5641578

\section{Keywords: Inflammation}

lipopolysaccharide

mouse

pulmonary mechanics

\section{Received: April 271999}

Accepted after revision September 141999

This study was supported by the Centers of Excellence Program (PRONEX-MCT), Brazilian Council for Scientific and Technological Development (CNPq), Rio de Janeiro State Research Supporting Foundation (FAPERJ), Financing for Studies and Projects (FINEP), and Fundação Universitária José Bonifácio (FUJB-UFRJ).
Lipopolysaccharide (LPS) is a constituent of the cell wall of gram-negative micro-organisms that contributes to the local inflammation and systemic toxicity of gramnegative infections [1]. In vivo administration of bacterial LPS triggers a network of inflammatory responses. LPS mediates many of its effects through ligand-receptor interaction with a number of immune cells, which is followed by the release of a vast array of pro-inflammatory mediators that orchestrate the acute inflammatory response [2]. The interaction is a complex one and depends on the level of circulating LPS as well as on cofactors such as lipopolysaccharide-binding protein [1, 2]. The activation of mononuclear phagocytes has a central role in this process, leading to the release of different cytokines, including tumor necrosis factor (TNF)$\alpha$, considered as one of the most important mediators of endotoxin-induced tissue injury $[1,3,4]$. TNF- $\alpha$ release induces neutrophil adherence to endothelial cells, favouring the migration and infiltration of neutrophils in pulmonary spaces $[2,4,5]$. The neutrophil recruitment induced by LPS inhalation has been described as dose and timedependent $[4,6,7]$. Besides its major defensive role, neutrophil activation causes the production of oxygen radicals and the release of granular enzymes, which can be associated with injurious processes, especially in the lung $[8,9]$. Different models of endotoxin-induced pulmonary injury have shown close correlations between neutrophil accumulation and tissue damage [10]. Nevertheless, the mechanism by which the cellular infiltration process during acute lung injury is modulated is still not completely known $[9,11]$.

In order to determine the pathogenic mechanisms involved in lung inflammation, many animal models have been developed [1, 4, 12-14]. Although less studied, the inhalation model of endotoxin-induced injury triggers a pulmonary inflammatory cascade similar to that observed with haematogenic dissemination $[2,4,5,13,15-17]$. It also mimics pulmonary inflammation secondary to natural exposure to LPS, being a model of direct pulmonary injury $[4,7,18]$.

Endotoxin-induced acute lung injury is also associated with respiratory mechanical changes represented by dynamic compliance reduction, and increased pulmonary resistance $[12,15,19,20]$. The mechanical changes have been attributed to the presence of pulmonary oedema, followed by ventilation-perfusion mismatch, or airway constriction 
[20]. However, it is not known whether the mechanical changes show similar time- and dose-dependences as described for the cellular recruitment. Furthermore, to the authors' knowledge no study on the correlation between functional changes and histopathological findings can be found in the literature.

Hence, the aims of the present study are to determine mice lung elastic, viscous, and viscoelastic changes after LPS inhalation, and to correlate these results with those from pulmonary histopathology and bronchoalveolar lavage fluid (BALF) analysis. Additionally, these parameters are also studied under two doses of LPS, and at different periods after inhalation.

\section{Materials and methods}

\section{Animal model}

Seventy-one male BALB/c mice, weighing 20-30 g, were randomly divided into three groups. The animals inhaled for 10 min either $2 \mathrm{~mL}$ of aerosolized saline $(\mathrm{NaCl}$ $0.9 \%)$, control group $(\mathrm{C} ; \mathrm{n}=24)$, or Escherichia coli LPS (lot 55:B5 from Difco Lab., Detroit, MI, USA) dissolved in $2 \mathrm{~mL}$ of saline at $0.3 \mathrm{mg} \cdot \mathrm{mL}^{-1}$ (group L0.3; $\mathrm{n}=24$ ) and 10 $\mathrm{mg} \cdot \mathrm{mL}^{-1}$ (group L10; $\mathrm{n}=23$ ). The inhalation chamber was made with a 1-L buchner adapted with conical glass tubes coupled to a manometer. Groups of 5-6 mice were put in the tubes to inhale saline or LPS. After inhalation each group was randomly divided into four sub-groups, related to the time when pulmonary mechanics were measured (3, 24,48 , and $72 \mathrm{~h}$ after inhalation).

The other five animals of each group were submitted to the same inhalation protocol described above in order to obtain aliquots of BALF. For this purpose, animals were anaesthetized with pentobarbital sodium $(12 \mathrm{mg} \cdot \mathrm{kg}$ body weight $^{-1}$ i.p.), tracheae were cannulated, and lungs washed eight times with $0.5 \mathrm{~mL}$ of saline to provide $4 \mathrm{~mL}$ of BALF. Aliquots of each BALF were used to evaluate neutrophil, protein, and TNF- $\alpha$ contents at 1, 3, 24, 48, and $72 \mathrm{~h}$ after inhalation of saline or LPS.

\section{Evaluation of bronchoalveolar lavage fluid}

Total cells present in the BALF were counted with a Coulter counter ZM (Coulter Electronics, Hialeah, FL, USA) and values expressed as number of cells per millilitre. Differential cell counts were performed after cytocentrifugation (Incibrás, Rio de Janeiro, Brazil) and staining with Diff-Quik stain (Baxter Dade AG, Dunding, Germany). At least 250 cells were counted and results were expressed as number of neutrophil population per millilitre.

After centrifugation of the BALF the supernatant was collected and stored at $-70^{\circ} \mathrm{C}$. The supernatant was then assayed for TNF- $\alpha$ and protein content. TNF- $\alpha$ levels in the BALF were determined by a highly specific enzyme linked immunosorbent assay (ELISA) with a detection limit of $50 \mathrm{pg} \cdot \mathrm{mL}^{-1}$. The assay system was established by using a rat anti-murine TNF- $\alpha$ monoclonal antibody, a rabbit anti-murine TNF- $\alpha$ polyclonal antibody (Genzyme Diagnostics, Cambridge, MA, USA) and a peroxidase- labelled goat anti-rabbit immunoglobulin ( $\mathrm{Ig}) \mathrm{G}$ (BioSys, Compiègne, France).

Protein content in the BALF was determined according to BRADFORD [21], using ovalbumin as standard. Briefly, the method is based on the observation that Coomassie Brilliant Blue G-250 exists in two different colour forms, red and blue. The red form is converted to the blue form upon binding to protein. The final concentrations in the reagent are 0.01 (weight $(\mathrm{w}) /$ volume $(V)$ ) Coomassie Brilliant Blue G-250, 4.7\% (w/v) ethanol, and 8.5\% (w/v) phosphoric acid.

\section{Pulmonary mechanics}

After inhalation the animals to be submitted to pulmonary mechanics analysis were sedated (diazepam 1 mg i.p.), and anaesthetized with pentobarbital sodium (20 $\mathrm{mg} \cdot \mathrm{kg}$ body weight ${ }^{-1}$ i.p.). Then, the mice were tracheotomized, and a snugly fitting cannula $(0.8 \mathrm{~mm}$ id) was introduced into the trachea. The anterior chest wall was surgically removed. Mechanical ventilation (model 683; Harvard Apparatus, Southnatick, MA, USA) with a frequency of 100 breaths $\mathrm{min}^{-1}$, a tidal volume $(V \mathrm{~T})$ of 0.2 $\mathrm{mL}$, and an adequate amount of positive end-expiratory pressure (PEEP) was applied right before the pleural cavity was entered. The PEEP level was determined as follows: before the pleural space was opened, the ventilator was disconnected at end expiration, and the airways were connected solely to the pressure transducer. After pleural incision, there was an increase in tracheal pressure $(P \operatorname{tr})$ that corresponded to the elastic recoil pressure of the lung at relaxation volume. Thereafter, the same pressure was applied to the lung $\left(\mathrm{PEEP}=2.0 \mathrm{cmH}_{2} \mathrm{O}\right)$, and the airways were reopened.

An adequate pneumotachograph $(1.5 \mathrm{~mm}$ id, length $=4.2$ $\mathrm{cm}$, distance between side ports $=2.1 \mathrm{~cm}$ ) constructed according to MORTOLA and NowORAJ [22] was connected to the tracheal cannula for the measurements of airflow $\left(V^{\prime}\right)$, and changes in tidal volume $(V \mathrm{~T})$. The pressure gradient across the pneumotachograph was determined by means of a Validyne MP45-2 differential pressure transducer (Engineering Corp., Northridge, CA, USA). The flow resistance of the equipment $(R \mathrm{eq})$, tracheal cannula included, was constant up to flow rates of 26 $\mathrm{ml} \cdot \mathrm{s}^{-1}$ and amounted to $0.13 \mathrm{cmH} \mathrm{H}_{2} \mathrm{O} \cdot \mathrm{mL}^{-1} \cdot \mathrm{s}$. Equipment resistive pressure $\left(=R \mathrm{eq} \cdot V^{\prime-1}\right)$ was subtracted from pulmonary resistive pressure so that the present results represent intrinsic values. Because abrupt changes of diameter were not present in the current circuit, errors of measurement of flow resistance were avoided [23]. The equipment dead space was $0.3 \mathrm{~mL}$. P tr was measured with a Validyne MP45-2 differential pressure transducer (Engineering Corp.). All signals were conditioned and amplified in a Beckman type R Dynograph (Beckman, Schiller Park, IL, USA). Flow and pressure signals were also passed through 8-pole Bessel filters (902LPF; Frequency Devices, Haverhill, MA, USA) with the corner frequency set at $100 \mathrm{~Hz}$, sampled at $200 \mathrm{~Hz}$ with a 12-bit analogue-todigital converter (DT-2801A; Data Translation, Marlboro, MA, USA), and stored on a microcomputer (PC-AT; IBM, Armonk, NY, USA). All data were collected using LABDAT software (RHT- InfoData Inc., Montreal, Quebec, Canada). 
Muscle relaxation was achieved with gallamine triethyliodide ( $2 \mathrm{mg} \cdot \mathrm{kg}$ body weight ${ }^{-1}$ i.p. $)$, and artificial ventilation was provided by a Samay VR15 constant flow ventilator (Universidad de la Republica, Montevideo, Uruguay). During the test breaths a 5-s end-inspiratory pause could be generated by adjusting the ventilator settings, whereas during baseline ventilation no pause was used. In order to avoid the effects of different $V^{\prime}$ and $V_{\mathrm{T}}$ [24], and thence inspiratory duration [25], on the measured variables, special care was taken to keep $V \mathrm{~T}(0.2 \mathrm{~mL})$ and $V^{\prime}(1$ $\left.\mathrm{mL} \cdot \mathrm{s}^{-1}\right)$ constant in all animals.

Pulmonary mechanics were measured from end-inspiratory occlusions after constant flow inflations [24, 26, 27]. In an open-chest preparation, $P$ tr reflects transpulmonary pressure $(P \mathrm{~L})$. After end-inspiratory occlusion, there is an initial fast drop in transpulmonary pressure $(\Delta P 1)$ from the preocclusion value down to an inflection point $(\mathrm{Pi})$ followed by a slow pressure decay $(\Delta P 2)$ until a plateau is reached. This plateau corresponds to the elastic recoil pressure of the lung $(P$ el $)($ fig. 1$) . \Delta P 1$ selectively reflects pressure dissipated against airway resistance in healthy animals and humans [26, 27], and $\Delta P 2$ reflects viscoelastic properties (stress relaxation) and/or inhomogeneities of lung tissue [27], together with a tiny contribution of pendelluft in normal situations $[26,28]$. Total pressure drop $(\Delta P$ tot $)$ is equal to the sum of $\Delta P 1$ and $\Delta P 2$. Static lung elastance ( $E$ st) was calculated by dividing $P$ el, measured at $5 \mathrm{~s}$ after end-inspiratory occlusion, by $V \mathrm{~T}$. Dynamic lung elastance (Edyn) was obtained by dividing Pi by $V$ T. $\Delta E$ was calculated as the difference $E$ dyn- $E$ st. The data concerning lung elastance was presented in terms of $E_{\text {st }}$ and $\Delta E$ instead of $E$ dyn since they represent, respectively, the elastic and viscoelastic properties of the lung. Pulmonary mechanics were measured at four different occasions (3, 24,48 , and $72 \mathrm{~h}$ ) after inhalation. Values are presented as mean \pm 1 SD of 10-15 determinations on each occasion in all groups.

The delay between the beginning and the end of the valve closure $(10 \mathrm{~ms})$ was allowed for by back extrapolation of the pressure records to the actual time of occlusion, and the corrections in pressure, although very minute, were performed as previously described [24].

Data analysis was performed with ANADAT software (RHT-InfoData Inc.).

\section{Histology and morphometry}

Morphometric analysis was performed in excised lungs at functional residual capacity. Immediately after the removal of the lungs en bloc, which took not longer than $90 \mathrm{~s}$, they were frozen by rapid immersion in liquid nitrogen. Frozen lungs were fixed in Carnoy's solution (ethanol-chloroform-acetic acid, 70:20:10) at $-70^{\circ} \mathrm{C}$ for $24 \mathrm{~h}$. Solutions with progressively increasing concentrations of ethanol at $-20^{\circ} \mathrm{C}$ were then substituted for Carnoy's until $100 \%$ ethanol was reached. The tissue was maintained at $20^{\circ} \mathrm{C}$ for $4 \mathrm{~h}$, warmed to $4^{\circ} \mathrm{C}$ for $12 \mathrm{~h}$, and then allowed to reach and remain at room temperature for $2 \mathrm{~h}$ [29]. After fixation, the tissue block obtained from midsagittal slices at the level of the axial bronchus of the left lung was embedded in paraffin. Slices ( $4 \mu \mathrm{m}$ thick) were obtained by means of a microtome. Slides were stained with haematoxylin-eosin. Morphometric analysis was performed with an integrating eyepiece with a coherent system made
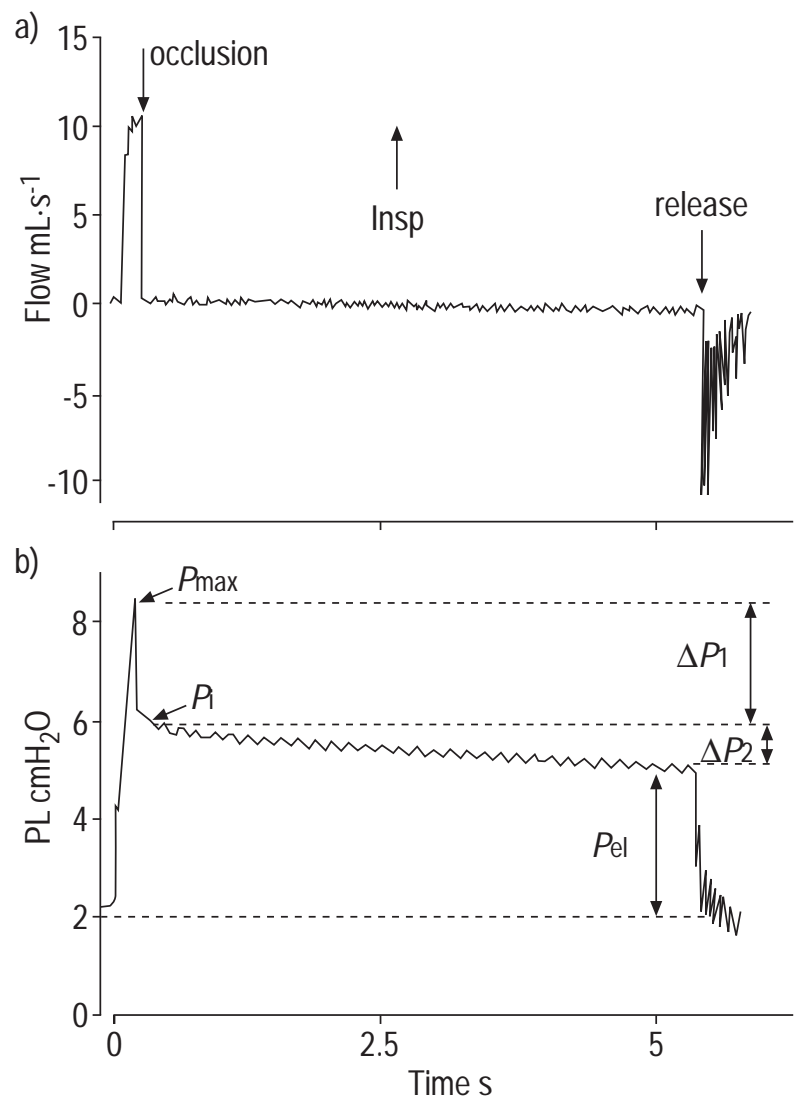

Fig. 1. - Tracings of flow and transpulmonary pressure $(P \mathrm{~L})$ from a mouse illustrating the experiments. a) End inspiratory occulsion is indicated by arrow and was maintained for $5 \mathrm{~s}$, when the airways were released. Positive end-expiratory pressure (PEEP) of $2 \mathrm{cmH}_{2} \mathrm{O}$ was used. Insp: inspiration. b) $\triangle P 1$ : pressure dissipated against airway resistance; $\triangle P 2$ : pressure dissipated against viscoelastic and/or inhomogeneous lung component; $P$ el: lung elastic recoil pressure; $P$ i: inflection point; $P$ max: maximal transpulmonary pressure.

of a 100-point grid consisting of 50 lines of known length coupled to a light microscope (Axioplan, Zeiss, Germany). Polymorphonuclear and mononuclear cells, pulmonary tissue and alveolar oedema were determined by the point-counting technique [30] across five random noncoincident microscopic fields at a $100 \times$ magnification in each sample. Points falling on tissue area and not over alveolar spaces were counted, and divided by the total number of points in each microscopic field. Thus, data were reported as the fractional area of pulmonary tissue $[30,31]$. The same method was applied to determine polymorphonuclear and mononuclear cells, and alveolar oedema.

\section{Statistical methods}

Student's t-test was used in order to compare the mechanical parameters and morphological variables gathered from control and LPS groups. The mechanical data obtained with the two doses of LPS were also compared. Firstly, the normality of the data (Kolmogorov-Smirnov test with Lilliefor's correction) and the homogeneity of variances (Levene median test) were tested. If both conditions were satisfied two-way analysis of variance (ANOVA) was used. If multiple comparisons were required StudentNewman-Keuls test was applied. 
Best Subsets Regression was performed in order to identify the relationship between functional and morphological data (dependent variables were represented by each functional parameter: $E$ st, $E$ dyn, $\Delta E, \Delta P 2$, and $\Delta P$ tot, predictive variables were represented by morphological data, i.e., alveolar oedema, total cell counting and pulmonary tissue area). The significance level was set at $5 \%$.

\section{Results}

Inspiratory flow and volume remained unaltered in groups C, L0.3, and L10 (table 1).

$E_{\text {st }}$ increased at 3 and $24 \mathrm{~h}$ after inhalation of 0.3 $\mathrm{mg} \cdot \mathrm{mL}^{-1}$ of LPS, returning to control values at 48 and $72 \mathrm{~h}$ (table 1). The other mechanical parameters $(\Delta E, \Delta P 1$, $\Delta P 2$, and $\triangle P$ tot) remained unaltered (table 1$)$.

After the inhalation of $10 \mathrm{mg} \cdot \mathrm{mL}^{-1}$ of LPS $E \mathrm{st}, \Delta \mathrm{E}$, and $\triangle P 2$ increased significantly at 3,24 , and $48 \mathrm{~h}$ (table 1 ). In addition, $\Delta P$ tot augmented at 24 and $48 \mathrm{~h}$. The greatest increase in $\Delta \mathrm{E}, \Delta P 2$, and $\Delta P$ tot occurred at $24 \mathrm{~h}$. Thereafter these parameters gradually decayed, reaching control values at $72 \mathrm{~h}$ (table 1$)$

Neutrophil recruitment, protein, and tumour necrosis factor- $\alpha$ in the bronchoalveolar lavage fluid

Inhalation of aerosolized LPS $\left(0.3\right.$ and $\left.10 \mathrm{mg} \cdot \mathrm{mL}^{-1}\right)$ induced a time and dose-dependent neutrophil recruitment into the BALF (figs. 2 and 3). One hour after inhalation, few neutrophils were detected. At $3 \mathrm{~h}$ this number increased, reaching the maximum level $24 \mathrm{~h}$ after stimulation. Neutrophil recruitment spontaneously decreased, and disappeared after $96 \mathrm{~h}$.

Inhalation of LPS was also followed by a time-dependent release of TNF- $\alpha$ into the BALF (figs. 2 and 3). One hour after inhalation of LPS the TNF- $\alpha$ concentration reached $50 \%$ of its maximal level, at a time when only few neutrophils were found, indicating that TNF- $\alpha$ synthesis precedes neutrophil recruitment. Maximal levels of TNF- $\alpha$ were measured in the BALF $3 \mathrm{~h}$ after inhalation of 0.3 and 10 mg.mL ${ }^{-1}$ LPS (figs. 2 and 3 ).

Additionally, no protein was detected after the inhalation of $0.3 \mathrm{mg} \cdot \mathrm{mL}^{-1}$ of LPS, while $10 \mathrm{mg} \cdot \mathrm{mL}^{-1}$ of LPS inhalation led to a time-dependent increase in protein level in the BALF, which showed characteristics along time similar to those of neutrophil recruitment (fig. 3).

\section{Morphometrical analysis}

Histopathological examination of the lungs demonstrated significantly increased total cellularity in relation to control in all instances $(3,24,48$, and $72 \mathrm{~h})$ in groups L0.3 and L10, being more intense at 24 and $48 \mathrm{~h}$ (table 2). The cellular increase was composed both by polymorph and mononuclear cells. Group L10 showed a greater fractional area of pulmonary tissue in relation to control at 24 and $48 \mathrm{~h}$ (table 2). No significant alveolar oedema was observed in any group (table 2). No airway constriction was observed.

Although both polymorph and mononuclear cell counting augmented, the percentage of polymorphonuclear increment in relation to total cells gradually increased until $48 \mathrm{~h}$, while the percentage of mononuclear cells decreased. Similar tendencies was observed in group L0.3, but to a smaller degree (table 2).

\section{Correlation between mechanical and morphometrical data}

The functional changes of $E_{\text {st }}$ at $3 \mathrm{~h}$ in group L0.3 were correlated with total cellularity provided by morphometry $(\mathrm{p}=0.02$ and $\mathrm{r}=\mathrm{O} .81)$. In group L10, Est at $24 \mathrm{~h}$ was also correlated with total cellularity $(\mathrm{p}=0.04$ and $\mathrm{r}=0.61) . \Delta E$ at

Table 1. - Mechanical variables after inhalation of saline, 0.3 or $10 \mathrm{mg} \cdot \mathrm{mL}^{-1}$ of Escherichia coli lipopolysaccharide

\begin{tabular}{|c|c|c|c|c|c|}
\hline & Group & $3 \mathrm{~h}$ & $24 \mathrm{~h}$ & $48 \mathrm{~h}$ & $72 \mathrm{~h}$ \\
\hline \multirow[t]{3}{*}{ Flow $\mathrm{mL} \cdot \mathrm{s}^{-1}$} & $\mathrm{C}$ & $1.05 \pm 0.01$ & $1.03 \pm 0.01$ & $1.03 \pm 0.01$ & $1.03 \pm 0.01$ \\
\hline & L0.3 & $1.03 \pm 0.03$ & $1.04 \pm 0.01$ & $1.04 \pm 0.02$ & $1.02 \pm 0.02$ \\
\hline & L10 & $1.04 \pm 0.04$ & $1.05 \pm 0.01$ & $1.05 \pm 0.01$ & $1.02 \pm 0.03$ \\
\hline \multirow[t]{3}{*}{ Volume $\mathrm{mL}$} & $\mathrm{C}$ & $0.20 \pm 0.01$ & $0.20 \pm 0.00$ & $0.19 \pm 0.01$ & $0.20 \pm 0.03$ \\
\hline & L0.3 & $0.19 \pm 0.01$ & $0.20 \pm 0.00$ & $0.20 \pm 0.01$ & $0.19 \pm 0.01$ \\
\hline & L10 & $0.19 \pm 0.00$ & $0.19 \pm 0.01$ & $0.20 \pm 0.00$ & $0.20 \pm 0.00$ \\
\hline \multirow{3}{*}{$E_{\text {st }} \mathrm{cmH}_{2} \mathrm{O} \cdot \mathrm{mL}^{-1}$} & $\mathrm{C}$ & $32.97 \pm 5.15$ & $37.72 \pm 2.43$ & $39.84 \pm 6.14$ & $32.79 \pm 2.82$ \\
\hline & L0.3 & $54.57 \pm 16.52 *$ & $45.60 \pm 7.10^{*}$ & $40.29 \pm 9.68$ & $32.79 \pm 2.82$ \\
\hline & L10 & $46.14 \pm 8.70 *$ & $53.21 \pm 10.72 *$ & $49.09 \pm 6.62 *$ & $38.89 \pm 11.16$ \\
\hline \multirow[t]{3}{*}{$\Delta E \mathrm{cmH}_{2} \mathrm{O} \cdot \mathrm{mL}^{-1}$} & $\mathrm{C}$ & $4.39 \pm 1.12$ & $4.57 \pm 0.83$ & $5.43 \pm 1.03$ & $4.69 \pm 0.26$ \\
\hline & L0.3 & $6.34 \pm 0.17$ & $5.23 \pm 0.75$ & $5.99 \pm 0.92$ & $4.69 \pm 0.26$ \\
\hline & L10 & $6.37 \pm 1.50^{*}$ & $10.53 \pm 3.33 *$ & $9.51 \pm 2.03 *$ & $5.61 \pm 0.78$ \\
\hline \multirow[t]{3}{*}{$\Delta P$ tot $\mathrm{cmH}_{2} \mathrm{O}$} & $\mathrm{C}$ & $1.49 \pm 0.35$ & $1.49 \pm 0.24$ & $1.60 \pm 0.28$ & $1.52 \pm 0.19$ \\
\hline & L0.3 & $1.89 \pm 0.53$ & $1.55 \pm 0.19$ & $1.68 \pm 0.10$ & $1.64 \pm 0.17$ \\
\hline & L10 & $1.78 \pm 0.38$ & $2.39 \pm 0.49 *$ & $2.26 \pm 0.36^{*}$ & $1.59 \pm 0.26$ \\
\hline \multirow[t]{3}{*}{$\Delta P 1 \mathrm{cmH}_{2} \mathrm{O}$} & $\mathrm{C}$ & $0.62 \pm 0.16$ & $0.59 \pm 0.07$ & $0.56 \pm 0.17$ & $0.58 \pm 0.18$ \\
\hline & L0.3 & $0.67 \pm 0.14$ & $0.52 \pm 0.19$ & $0.50 \pm 0.11$ & $0.61 \pm 0.12$ \\
\hline & L10 & $0.52 \pm 0.12$ & $0.40 \pm 0.15$ & $0.40 \pm 0.10$ & $0.48 \pm 0.12$ \\
\hline \multirow[t]{3}{*}{$\Delta P 2 \mathrm{cmH}_{2} \mathrm{O}$} & $\mathrm{C}$ & $0.87 \pm 0.22$ & $0.90 \pm 0.17$ & $1.04 \pm 0.20$ & $0.94 \pm 0.05$ \\
\hline & L0.3 & $1.22 \pm 0.45$ & $1.03 \pm 0.16$ & $1.18 \pm 0.19$ & $1.04 \pm 0.25$ \\
\hline & L10 & $1.25 \pm 0.32 *$ & $1.99 \pm 0.61 *$ & $1.86 \pm 0.42 *$ & $1.11 \pm 0.17$ \\
\hline
\end{tabular}

Mean values \pm SD of 6-8 animals per group (8-10 determinations per animal) observed at 3, 24, 48, and $72 \mathrm{~h}$ after inhalation of saline (C) or $0.3 \mathrm{mg} \cdot \mathrm{mL}^{-1}$ (L0.3) or $10 \mathrm{mg} \cdot \mathrm{mL}^{-1}$ (L10) of $E$. Coli lipopolysaccharide. Est: static elastance; $\Delta E$ : difference between pulmonary dynamic and static elastances; $\Delta P$ tot: total pulmonary pressure variation; $\Delta P 1$ : pressure dissipated against airway resistance; $\Delta P 2$ : pulmonary viscoelastic/inhomogeneous pressure change. $*$ : $\mathrm{p}<0.05$, compared to control group. 


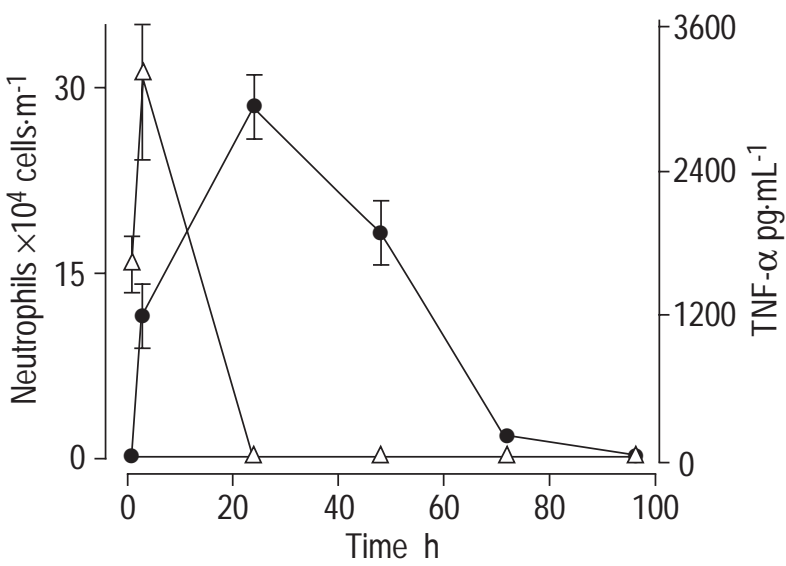

Fig. 2. - Data are presented as mean \pm SEM. Neutrophil $(\mathbf{O})$ and tumour necrosis factor (TNF)- $\alpha(\triangle)$ recruitment in the bronchoalveolar lavage fluid with time after inhalation of $0.3 \mathrm{mg} \cdot \mathrm{mL}^{-1}$ of Escherichia coli lipopolysaccharide. Each point is the average of three mice.

3 and $24 \mathrm{~h}(\mathrm{p}=0.02$ and $\mathrm{r}=0.41 ; \mathrm{p}=0.01$ and $\mathrm{r}=0.80$, respectively), and $\Delta P 2$ and $\Delta P$ tot at $24 \mathrm{~h}$ in group L10 $(\mathrm{p}=0.01$ and $\mathrm{r}=0.80 ; \mathrm{p}=0.006$ and $\mathrm{r}=0.83$, respectively) were significantly correlated with the fractional area of pulmonary tissue.

\section{Discussion}

Experimental models using endotoxin have been largely applied to study pulmonary inflammatory injury. They can mimic morphological and functional changes observed in clinical situations secondary to the presence of circulating lipopolysaccharide [2, 4, 13, 15-17]. These models also allow the analysis of bronchial responsiveness to exposure to pro-inflammatory agents in room air [7, 17].

In group L10 $\Delta \mathrm{E}, \Delta P 2$, and $\Delta P$ tot also augmented, suggesting a greater pressure dissipation to overcome pulmonary viscoelastic and/or inhomogeneous components. The elastic and viscoelastic changes returned to control values after $72 \mathrm{~h}$. These findings were concomitant with those observed in neutrophil recruitment in the BALF (fig. 3 ) and at the histological level (table 2). Interestingly, in 1990 WheELER et al. [19] observed the improvement in pulmonary resistance and compliance $6 \mathrm{~h}$ after TNF- $\alpha$ infusion.

In the present work elastance changes were significantly correlated with increased cellularity, whereas $\Delta E, \Delta P 2$, and $\Delta P$ tot changes were related to the fractional area of pulmonary tissue. These data are in agreement with the viscoelasticity theory that describes a close correlation between viscoelastic parameters and tissue characteristics [26, 27]. These correlations were also observed in noninflammatory experimental models using the end-inflation occlusion method [33]. No significant alveolar oedema (table 2) or airway constriction was observed.

In a model of endotoxin-induced acute lung injury EsBENSHADE et al. [20] examined the relationships between lung mechanics and pulmonary oedema over time during the development of respiratory failure. The authors observed an increase in pulmonary resistance and decrease in dynamic compliance, which occurred too early after endotoxin infusion to be due to pulmonary oedema [20]. In their work the degree of pulmonary oedema failed to
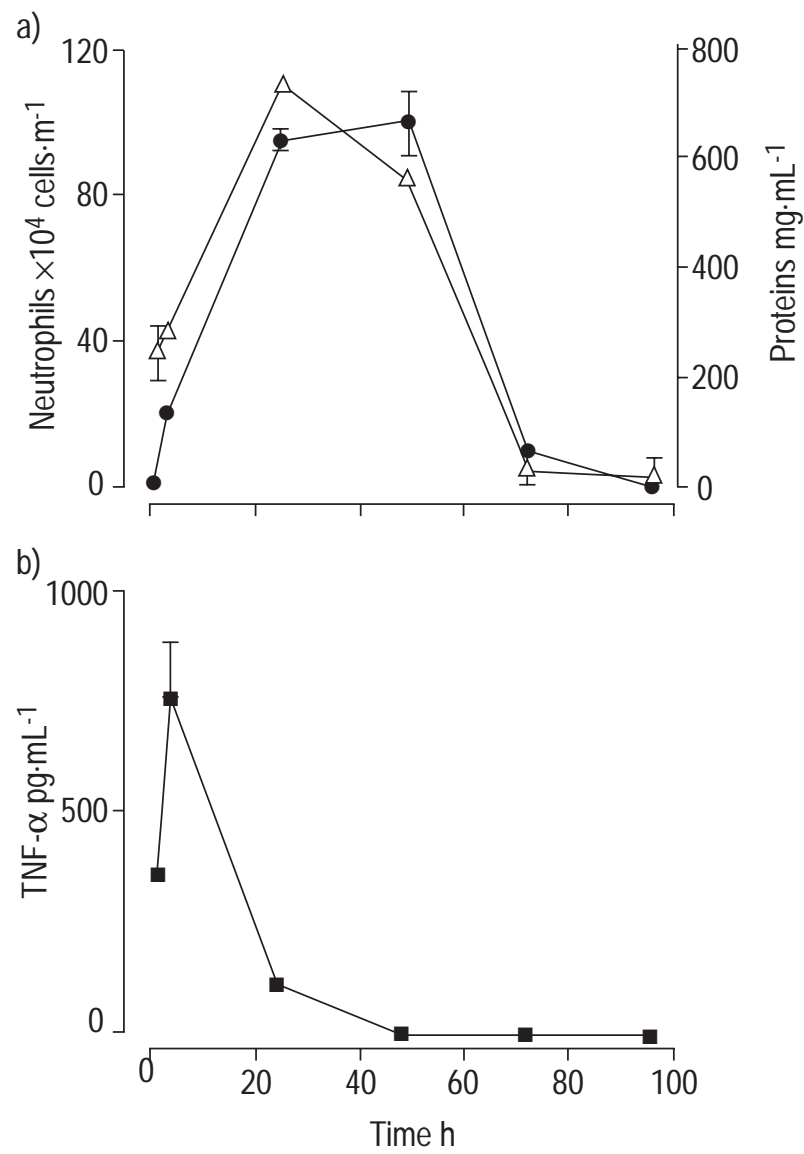

Fig. 3. - Data are presented as meansem. Neutrophil ( $)$ and proteins $(\triangle)$ and b) tumour necrosis factor (TNF)- $\alpha$ ( $)$ recruitment in the bronchoalveolar lavage fluid with time after inhalation of $10 \mathrm{mg} \cdot \mathrm{mL}^{-1}$ of Escherichia coli lipopolysaccharide. Each point is the average of three mice.

correlate with other measured mechanical variables. In this line the present study did not show any correlation between elastance and alveolar oedema. The absence of correlation between functional changes and alveolar oedema in response to endotoxin was also referred to by FeHRENBACH et al. [34]. The authors, using a model of perfused LPS, excluded the presence of pulmonary oedema as a potential cause of protein increase in the BALF, since it could not be demonstrated even at ultrastructural level. Other authors did not observe changes in extravascular lung water after LPS tracheal instillation, by means of gravimetric determination of extravascular water and dry weight [35].

It has been suggested that active airway constriction could be caused by the release of endogenous mediators following endotoxemia $[15,20]$. In the present work histopathological analysis did not show airway constriction. Additionally, no increases in $\Delta P 1$ could be observed, which suggests no changes in central airway responsiveness (table 1). However, the increased fractional area of pulmonary tissue reflects the presence of alveolar collapsed areas with the higher dosis of LPS. This histopathological change was correlated with the increased viscoelastic parameters $(\Delta E, \Delta P 2)$ thus indicating that tissue and/or small airway involvement is responsible for the increased pulmonary resistance found in the face of LPS 
Table 2. - Morphometric data after inhalation of saline and 0.3 or $10 \mathrm{mg} \cdot \mathrm{mL}^{-1}$ of Escherichia coli lipopolysaccharide

\begin{tabular}{llcccc}
\hline & Group & $3 \mathrm{~h}$ & $24 \mathrm{~h}$ & $48 \mathrm{~h}$ & $72 \mathrm{~h}$ \\
\hline Total cellularity fractional area & $\mathrm{C}$ & $8.4 \pm 3.0$ & $9.9 \pm 1.2$ & $6.4 \pm 1.1$ & $9.6 \pm 0.9$ \\
& $\mathrm{~L} 0.3$ & $21.1 \pm 4.4^{*}$ & $20.0 \pm 6.8^{*}$ & $11.8 \pm 0.8^{*}$ & $13.9 \pm 2.9^{*}$ \\
& $\mathrm{~L} 10$ & $21.0 \pm 4.4^{*}$ & $23.3 \pm 3.8^{*}$ & $25.0 \pm 6.2^{*}$ & $12.1 \pm 1.2^{*}$ \\
PMN fractional area & $\mathrm{C}$ & $1.3 \pm 0.6$ & $1.9 \pm 1.2$ & $1.2 \pm 0.4$ & $1.3 \pm 0.8$ \\
& $\mathrm{~L} 0.3$ & $5.9 \pm 1.3^{*}$ & $7.4 \pm 3.1^{*}$ & $3.3 \pm 0.9^{*}$ & $4.3^{*} \pm 3^{*}$ \\
& $\mathrm{~L} 10$ & $9.1 \pm 1.8^{*}$ & $11.5 \pm 3.6^{*}$ & $13.2 \pm 4.9^{*}$ & $5.0 \pm 1.3^{*}$ \\
MN fractional area & $\mathrm{C}$ & $7.1 \pm 2.4$ & $8.0 \pm 1.3$ & $5.2 \pm 0.9$ & $8.3 \pm 0.2$ \\
& $\mathrm{~L} 0.3$ & $15.2 \pm 3.7^{*}$ & $12.6 \pm 4.4$ & $8.3 \pm 1.0^{*}$ & $9.6 \pm 2.3$ \\
Pulmonary tissue fractional area & L10 & $11.9 \pm 3.0^{*}$ & $11.9 \pm 1.1^{*}$ & $11.8 \pm 2.5^{*}$ & $7.1 \pm 1.0^{*}$ \\
& $\mathrm{C}$ & $58.8 \pm 2.4$ & $57.8 \pm 4.8$ & $55.5 \pm 6.1$ & $61.2 \pm 6.8$ \\
& $\mathrm{~L} 0.3$ & $55.2 \pm 8.6$ & $61.9 \pm 5.1$ & $39.7 \pm 14.8$ & $60.7 \pm 8.5$ \\
Alveolar oedema fractional area & L10 & $62.1 \pm 6.2$ & $73.4 \pm 3.7^{*}$ & $73.1 \pm 3.7^{*}$ & $55.4 \pm 2.3$ \\
& $\mathrm{C}$ & $0.4 \pm 0.3$ & $0.0 \pm 0.0$ & $0.0 \pm 0.0$ & $0.5 \pm 0.3$ \\
& L0.3 & $0.4 \pm 0.1$ & $0.3 \pm 0.3$ & $0.1 \pm 0.2$ & $0.1 \pm 0.2$ \\
& L10 & $0.3 \pm 0.3$ & $0.2 \pm 0.4$ & $0.2 \pm 0.3$ & $0.1 \pm 0.2$ \\
\hline
\end{tabular}

Mean values \pm SD of 6-8 animals per group (five fields per animal) observed at 3, 24, 48, and $72 \mathrm{~h}$ after inhalation of saline (C) or 0.3 $\mathrm{mg} \cdot \mathrm{mL}^{-1}(\mathrm{~L} 0.3)$ or $10 \mathrm{mg} \cdot \mathrm{mL}^{-1}$ (L10) of E. coli lipopolysaccharide. PMN: polymorphonuclear cells; MN: mononuclear cells. *: $\mathrm{p}<0.05$, compared to control group.

administration. These findings are in accordance with the previous description of LPS-induced alterations of intracellular and alveolar surfactant [34], which could favour alveolar collapse. There are no previous reports demonstrating that the effects of LPS occur at the lung periphery.

Lung histopathological analysis showed increased total cellularity, and increased polimorpho- and mononuclear count after LPS administration (table 2). Lung cellularity was similar to that observed in the BALF (also time- and dose-dependent), and agreed with the literature [6, 15]. Group L10 showed an increased fractional area of pulmonary tissue at 24 and $48 \mathrm{~h}$ (table 2 ). This finding could have been secondary to a higher number of alveolar collapsed areas and/or an increased amount of polymorphonuclear cells.

The acute inflammatory lung injury obtained in this study was characterized by TNF- $\alpha$ production, which preceded neutrophil recruitment in the BALF. This finding is in accordance with the literature, as TNF- $\alpha$ has been considered as a main mediator of endotoxin-induced tissue injury $[1,3,4,19]$, favouring neutrophil infiltration in pulmonary spaces $[2,4,5]$. The neutrophil influx after LPS inhalation was time-dependent, with higher values observed at 24-48 $\mathrm{h}$ and followed by a posterior decrease, reaching control values at $72 \mathrm{~h}$ (fig. 2 and 3). Neutrophil recruitment was higher in group L10, supporting its dosedependence. These results agree with previous studies in animals [4] and humans [7]. GonçALves de Moraes et al. [4] observed a time- and dose-dependent neutrophil recruitment in the BALF in an experimental model of LPS inhalation in mice. Other authors also reported a dose- and time-dependent effect on neutrophil recruitment after LPS administration [1, 5, 6]. Additionally, group L10 showed an increased protein content in the BALF at 24 and $48 \mathrm{~h}$. In the present study BALF data closely followed the histopathological findings. Although the presence of protein has been considered as an indicator of the severity of pulmonary permeability change $[6,16]$ in the present study it was not accompanied by alveolar or interstitial oedema. The protein obtained in the BALF could have been the result of local liberation of inflammatory mediators since no alveolar oedema was found in the histopathological analysis. Another explanation could be the stimulatory effect of alveolar endotoxin on alveolar fluid clearance as demonstrated by GARAT et al. [35]. In a model of tracheally instilled LPS in rats, GARAT et al. [35] observed no changed in extravascular lung water and lung permeability to protein, although a marked increase in inflammatory cells in the air spaces was detected.

In conclusion, the pulmonary mechanical changes following lipopolysaccharide inhalation observed in the present study were dose- and time-dependent. The correlation between mechanical parameters and endotoxin dosis was especially noticeable for the viscoelastic changes, as the elastic changes allowed only a time correlation. The viscoelastic as well as the elastic changes obtained in the present work were correlated with the inflammation severity, as expressed by histopathological and bronchoalveolar lavage fluid analysis.

Acknowledgements. The authors are grateful to A.C. de Sonza Quaresma for skillful technical assistance.

\section{References}

1. Watson RWG, Redmond HP, Bouchier-Hayes D. Role of endotoxin in mononuclear phagocyte-mediated inflammatory responses. J Leukoc Biol 1994; 56: 95-103.

2. Ulich TR, Yin S, Remick DG, Russell D, Eisenberg SP, Kohno T. Intratracheal administration of endotoxin and cytokines. IV. The soluble tumor necrosis factor receptor type I inhibits acute inflammation. Am J Pathol 1993; 142: $1335-1338$.

3. Beutler B, Cerami A. Cachectin: more than a tumor necrosis factor. $N$ Engl J Med 1987; 316: 379-385.

4. Gonçalves de Moraes VL, Vargaftig BB, Meager A, Chignard M. Effect of cyclo-oxygenase inhibitors and modulators of cyclic AMP formation on lipopolysaccharide-induced neutrophil infiltration in mouse. $\mathrm{Br} J$ Pharmacol 1996; 117: 1792-1796.

5. Albelda SM, Smith CW, Ward PA. Adhesion molecules and inflammatory injury. FASEB $J$ 1994; 8: 504-512. 
6. Brieland JK, Kunkel RG, Fantone JC. Pulmonary alveolar macrophage function during acute inflammatory lung injury. Am Rev Respir Dis 1987; 135: 1300-1306.

7. Michel O, Nagy A-M, Schroeven M, et al. Dose-response relationship to inhaled endotoxin in normal subjects. Am J Respir Crit Care Med 1997; 156: 1157-1164.

8. Olivier D, Pesci A, Bertorelli G. Immunological defences in airways. In: Chrètien J, Dusser D, eds. Environmental Impact on the Airways. From Injury to Repair. Vol. 3. New York, USA, Marcel Dekker Inc., 1996; pp. 43-69.

9. Sibille Y, Reynold HY. Macrophages and polymorphonuclear neutrophils in lung defense and injury. $\mathrm{Am} \mathrm{Rev}$ Respir Dis 1990; 141: 471-501.

10. Steinberg KP, Milberg JA, Martin TR, Maunder RJ, Cockrill BA, Hudson LD. Evolution of bronchoalveolar cell populations in the adult respiratory distress syndrome. Am Respir Crit Care Med 1994; 150: 113-122.

11. Kollef MH, Schuster D. The acute respiratory distress syndrome. N Engl J Med 1995; 332: 27-37.

12. Hinson JM Jr, Hutchison AA, Ogletree ML, Brigham KL, Snapper JR. Effect of granulocyte depletion on altered lung mechanics after endotoxemia in sheep. $J$ Appl Physiol 1983; 55: 92-99.

13. Delclaux C, Rezaiguia-Delclaux S, Delacourt C, BrunBuisson C, Lafuma C, Harf A. Alveolar neutrophils in endotoxin-induced and bacteria-induced acute lung injury in rats. Am J Physiol 1997; 273: L104-L112.

14. Ulich TR, Yin S, Remick DG, Russell D, Eisenberg SP, Kohno T. Intratracheal administration of endotoxin and cytokines. IV. The soluble tumor necrosis factor receptor type I inhibits acute inflammation. Am J Pathol 1993; 142: 1335-1338.

15. Burrell R, Lantz RC, Hinton DE. Mediators of pulmonary injury induced by inhalation of bacterial endotoxin. $A m$ Rev Respir Dis 1988; 137: 100-105.

16. Brigham KL, Bowers RE, Haynes J. Increased sheep lung vascular permeability caused by Escherichia coli endotoxin. Circ Res 1979; 45: 292-297.

17. Pauwels RA, Kips JC, Peleman RA, Van Der Straeten ME. The effects of endotoxin inhalation on airway responsiveness and cellular influx in rats. Am Rev Respir Dis 1990; 141: 540-545.

18. Meyrick BO, Ryan US, Brigham KL. Direct effects of $E$. coli endotoxin on structure and permeability of pulmonary endothelial monolayers and the endothelial layer of intimal explants. Am J Pathol 1986; 122: 140-151.

19. Wheeler AP, Jesmok G, Brigham KL. Tumor necrosis factor's effects on lung mechanics, gas exchange, and airway reactivity in sheep. J Appl Physiol 1990; 68: 2542-2549.

20. Esbenshade AM, Newman JH, Lams PM, Jolles H, Brigham KL. Respiratory failure after endotoxin infusion in sheep: lung mechanics and lung fluid balance. $J$ Appl Physiol 1982; 53: 967-976.

21. Bradford MM. A rapid and sensitive method for the quantification of microgram quantities of protein utilizing the principle of protein-dye binding. Anal Biochem 1976; 72 : 248-254.

22. Mortola JP, Noworaj A. Two-sidearm tracheal cannula for respiratory airflow measurements in small animals. $J \mathrm{Appl}$ Physiol 1983; 55: 250-253.

23. Chang HK, Mortola JP. Fluid dynamic factors in tracheal pressure measurement. J Appl Physiol 1981; 51: 218225.

24. Kochi T, Okubo S, Zin WA, Milic-Emili J. Flow and volume dependence of pulmonary mechanics in anesthetized cats. J Appl Physiol 1988; 64: 441-450.

25. Similowski T, Levy P, Corbeil C, et al. Viscoelastic behavior of lung and chest wall in dogs determined by flow interruption. J Appl Physiol 1989; 67: 2219-2229.

26. Bates JHT, Rossi A, Milic-Emili J. Analysis of the behavior of the respiratory system with constant inspiratory flow. J Appl Physiol 1985; 58: 1840-1848.

27. Bates JHT, Ludwig MS, Sly PD, Brown K, Martin JG, Fredberg JJ. Interrupter resistance elucidated by alveolar pressure measurement in open-chest normal dogs. $J$ Appl Physiol 1988; 65: 408-414.

28. Otis AB, McKerrow CB, Bartlett RA, et al. Mechanical factors in distribution of pulmonary ventilation. $J \mathrm{Appl}$ Physiol 1956; 8: 427-443.

29. Nagase T, Lei M, Robatto FM, Eidelman DH, Ludwig MS. Tissue viscance during induced constriction in rabbit lungs: morphological-physiological correlations. $J$ Appl Physiol 1992; 73: 1900-1907.

30. Gundersen HJG, Bendtsen TF, Korbo L, et al. Some new, simple and efficient stereological methods and their use in pathological research and diagnosis. Acta Pathol Microbiol Immunol Scand 1988; 96: 379-394.

31. Capelozzi VL, Saldiva PHN, Antonangelo L, et al. Quantitation in inflammatory pleural disease to distinguish tuberculous and paramalignant from chronic nonspecific pleutritis. J Clin Pathol 1997; 50: 935-940.

32. Bates JHT, Baconnier P, Milic-Emili J. A theoretical analysis of interrupter technique for measuring respiratory mechanics. J Appl Physiol 1988; 64: 2204-2214.

33. Powers SR, Mannal R, Neclerio M, et al. Physiologic consequecences of positive end-expiratory pressure (PEEP) ventilation. Ann Surg 1973; 178: 265-271.

34. Fehrenbach H, Brasch F, Uhlig S, et al. Early alterations in intracellular and alveolar surfactant of the rat lung in response to endotoxin. Am J Respir Crit Care Med 1998; 157: 1630-1639.

35. Garat C, Rezaiguia S, Meignan M, et al. Alveolar endotoxin increases alveolar liquid clearance in rats. $J \mathrm{Appl}$ Physiol 1995; 79: 2021-2028. 